of this kind with no animal reservoir of infection can be maintained only in large human populations; these circumstances came only when the Roman Empire had grown to the point that it had cities with populations of around 500000 . Retrospective diagnosis suggests that smallpox hit the Romans in $\mathrm{AD} 150$ and measles 100 years later-with consequences almost as devastating as their later effects in the Caribbean.

The point of this potted history is that smallpox and measles have one last, crucial feature in common: they can be eliminated by medical intervention. The combination of an effective vaccine with lack of an animal reservoir or a human carrier state means that vaccination can eradicate the disease. The World Health Organisation has already achieved this goal with smallpox ${ }^{2}$; measles could be the next human disease to become extinct. ${ }^{3}$

Indeed, in the United States there is every prospect that measles will be extinct by 1984 ; this year fewer than 2000 cases have been notified. The reason is very simple. American children have been vaccinated against measles as routine for 10 years; in all States in the United States children cannot enter school unless they have been vaccinated against all the common infections, and $97 \%$ of children entering kindergarten are now vaccinated. ${ }^{4}$

Here in Britain the Department of Health and Social Security still seems to live in the same state of ignorance as Hippocrates. Despite an average of 100000 cases of measles a year and over 20 deaths (twice the average rate for whooping cough), the Department seems to have no campaign to persuade the public to accept measles vaccination, and fewer than half our children have been protected. ${ }^{3}$ The vaccine is effective and safe. Why, as we ask elsewhere in our editorial columns this week ( $p$ 1764), is Britain so often among the last of the technically advanced countries to adopt effective programmes of preventive medicine?

\footnotetext{
' McNeill WH. Plagues and peoples. Oxford: Basil Blackwell, 1976.

2 Anonymous. Smallpox and vaccination. Br Med F 1981;282:1880.

${ }^{3}$ Noah MD. Measles eradication policies. Br Med f 1982;284:997-8.

- Anonymous. Measles surveillance. Weekly Epidemiological Record 1982; 57:367.
}

\section{Need our streets be so filthy?}

Asked anecdotally about what they dislike about Britain, visitors often cite the high prices of our hotels and the filthiness of our streets. Conversely, many tourists from this country will instance the cleanliness of others as being part of the pleasure they get from travelling there, only to mention the shock when they return of noticing anew our litter strewn pavements and gutters full of cans, bottles, and dog excrement, to say nothing of the similar defilement of our roads, railways, and countryside. Representatives at this year's Annual Meeting of the BMA in London showed their concern when they gave priority to debating a motion that Britain's lack of cleanliness in public spaces, buildings, and conveniences was a national disgrace and demanded remediable action.

This year's representatives had only, however, to look outside the Logan Hall, where the ARM was held, to see examples of what they were talking about. Possibly the streets of the London Borough of Camden (where the BMA is a major ratepayer) are no more or less dirty than those of many other boroughs. Possibly, also, as an inner city area, its resources are more stretched than those elsewhere, with its large stocks of old housing and a shifting, mainly poor population. Nevertheless, with its numerous central hotels and sightseeing attractions, Camden is also an important area for tourists, and, given that a neighbouring borough has energetically tackled its litter problems, it must be asked why Camden and other boroughs do not try the same.

Of three possible approaches to this problem, oneexhortation ("Keep Britain Tidy")-manifestly does not work, and another-enforcing the law which prescribes fines for litter offences-is rarely tried. A third-prevention-should be. The City of Westminster has persuaded local firms and organisations to sponsor brightly painted stout litter bins throughout the streets of the central area. Not surprisingly these are used and the Westminster streets seem distinctly cleaner than those elsewhere. In Camden litter bins are less conspicuous, smaller, and sparser; among the streets flanking six Bloomsbury squares near BMA House, for example, there are a total of only seven litter bins. With nowhere to put their rubbish, self evidently people copy others and throw it on to the ground. Moreover, the problem is compounded by the increasing practice of shops leaving their rubbish (including food and bottles) in the streets overnight either in unfastened bags or loose in fragile cardboard boxes-which the rain reduces to a pulp or the wind distributes around. Anybody who travels through, say, Kingsway in the early morning can see the result: filth all over the pavement and road.

London is by no means the only city in Britain with such problems, nor was it always so dirty. Our people surely have the right to the same standards of public cleanliness as in other civilised countries. Local authorities and others should ensure that these are provided, and maintained.

\section{Do it yourself obituaries}

The obituaries are one of the most read sections of the $B M \mathcal{F}$, yet they are not without their faults and could be much improved. Their main defect is obvious to anybody in our office who has to read a dozen obituary proofs all at once. All 12 seem to be the obituaries of saints. An assorted collection of general practitioners, orthopaedic surgeons, forensic psychiatrists, and ex-presidents of various colleges might normally be expected to include a few individuals who were overassertive, pompous, unhelpful to their juniors, talked too much, were mean, or were clumsy with their hands. Yet neither in the $B M \mathcal{F}$ nor in the Lancet is there more than an occasional hint of imperfection. The Times may print considered judgments of leading statesmen, entertainers, and artists; the medical profession seems to prefer a postmortem coat of whitewash.

The tradition has long been that obituaries printed in the $B M F$ should be written in accordance with the maxim "speak only good of the dead." Dr John Rowan Wilson, who at one time was the BMF's obituarist, was one of the first to explain the code of understatement and platitudes, while Dr Richard Gordon, who also briefly oversaw $B M \mathcal{F}$ obituaries, said that he learnt to write fiction while writing them. "Plainspoken" in a $B M F$ obituary is, all too often, a euphemism for offensive; "a perfectionist" may well have been an obsessional neurotic.

Yet to write an unswervingly honest obituary about a col- 
league who has just died must necessarily be very difficult if not impossible (which is why newspapers arrange for their obituaries to be written in advance). Grief, or at least a sudden reminder of mortality, clouds the judgment of the immediate obituarist and clots the adjectives; and the feelings of family and friends of the deceased have to be remembered as well. So how can we move away from these anodyne, encoded obituaries as well as ensuring that all the important facts are accurately presented ? One possible and serious alternative is to encourage people to write their own obituaries. Most doctors reach the age of retirement, and as most readers are primarily interested in doctors' professional lives a "preobituary" written at this time could form the bulk of the notice that would actually appear. Colleagues might, when death strikes, append a few sentences to say that the dead doctor had gone on to breed his own rose.

Such do it yourself obituaries would, we hope, be more honest, telling us of a man's disappointments and failures as well as his successes. But even if they were not they would at least be accurate, include the information that the dead doctor wanted included, and be more colourful and personal. We do already receive some obituaries that people have written for themselves, and they mostly have the qualities we seek. We will welcome contributions from doctors retiring or from any who feel themselves weakening.

\section{A law that must be enforced}

At the end of January 1983 Britain will belatedly join the rest of the civilised world in requiring seat belts to be worn by car drivers and their front passengers. Britain's law comes over 10 years after some more enlightened countries introduced legislation (and several of these pioneers have now also made wearing seat belts compulsory for rear passengers), but the delay cannot be blamed on ignorance. The BMA has consistently pressed for this reform as part of the medical campaign for improvements in road safety. Thousands of people must have died unnecessarily and cruelly because of the pusillanimous failure of successive governments to practise in Britain what has been proved to work elsewhere.

Nevertheless, to introduce the Act is still not enough: the law must be enforced. Too many of Britain's traffic laws are now ignored-both the old (such as on speed limits, noise, and diesel fume pollution) and the new (such as on using dipped headlights in poor visibility, bus lanes, and heavy vehicles parking overnight in residential areas). The first few months will be crucial. Chief constables must ensure that their police forces are left in no doubt of the importance of convincing the public that this law will be enforced, so that within a year seat belts will have become as generally accepted as crash helmets.
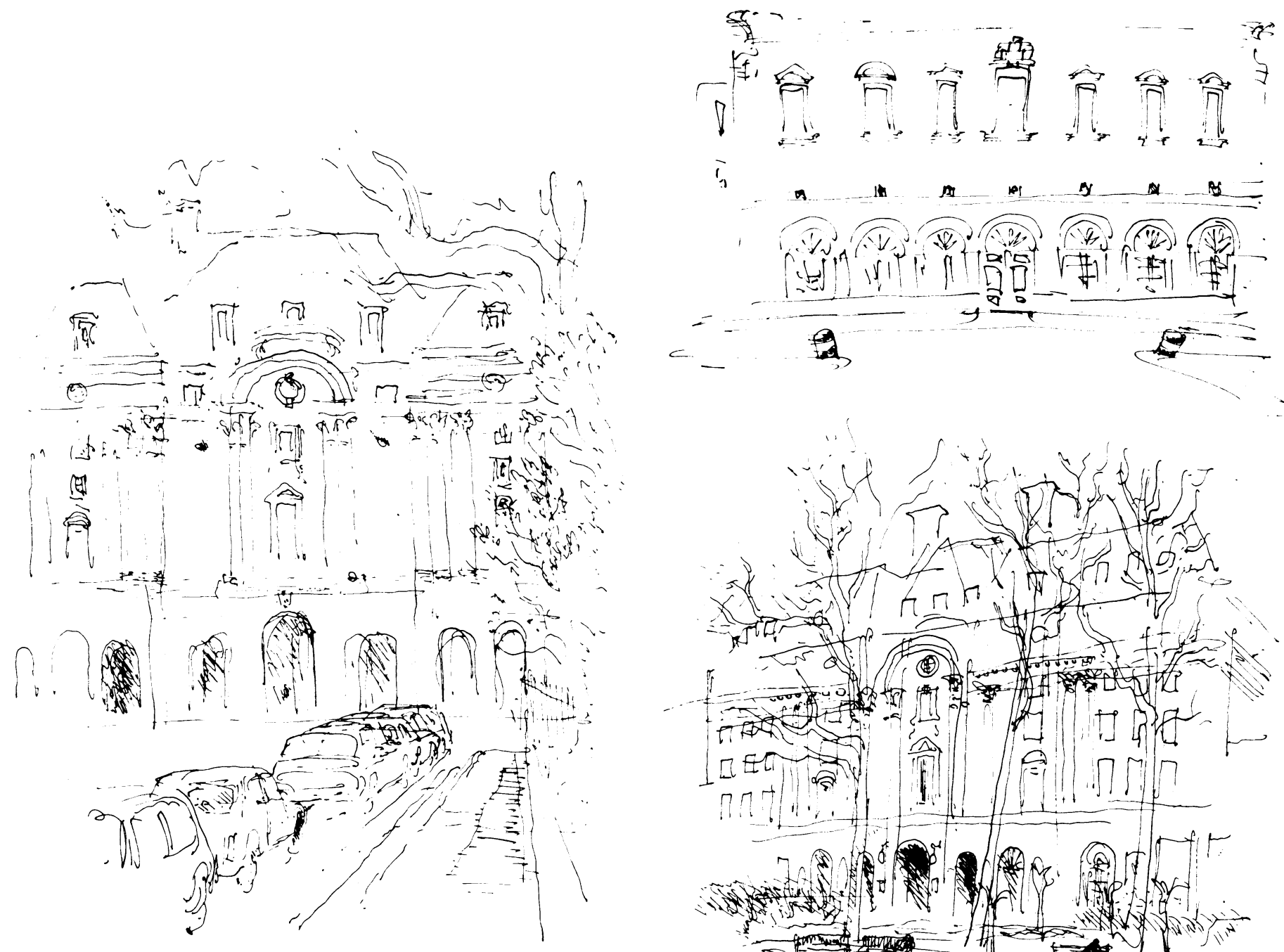

Three views of BMA House by David Gentleman. Above and right from Tavistock Square and above right from Burton Street. 